\title{
Prediction of the vibratory properties of ship models with realistic structural configurations produced using additive manufacturing
}

\author{
Apostolos Grammatikopoulos*, Joseph Banks, Pandeli Temarel \\ Fluid-Structure Interactions Group, University of Southampton, Boldrewood Innovation \\ Campus, Burgess Rd, SO17 6QF Southampton, United Kingdom
}

\begin{abstract}
The use of flexible ship models to determine the dynamic behaviour of fullscale ships in waves and to compare the accuracy of numerical predictions has increased in the past few years. Segments attached to a flexible uniform backbone of suitable but simple cross section is the preferred solution. Although such models are relatively easy to manufacture with conventional processes, they do not represent accurately the structural detail, for example, of a container ship. The limitations of conventional manufacturing constraints can be potentially overcome by use of modern technologies such as additive manufacturing. Designing detailed elastic ship models requires the determination of dynamic material properties, in addition to the manufacturer mechanical properties.

In this investigation, a detailed but easy-to-implement method is developed, and applied to a uniform container ship-like model, to identify the material properties that are relevant to the calculation of the natural frequencies of 3D printed thin-walled structures. It is demonstrated that modal testing of 3D printed specimens, combined with FEA modelling, can be used to accurately predict the natural frequencies of much more complex thin-walled structures. This method allows investigators to acquire all information necessary during the design stage of 3D printed structures without having to resort to full material characterisation.
\end{abstract}

Keywords: additive manufacturing, cellular, modal testing, structural vibration, thin-walled girders

\footnotetext{
* Corresponding author

Email addresses: A.Grammatikopoulos@soton.ac.uk (Apostolos Grammatikopoulos*), J.Banks@soton.ac.uk (Joseph Banks), P.Temarel@soton.ac.uk (Pandeli Temarel)
} 


\section{Introduction}

Structures with the geometry of a thin-walled girder are common in various engineering applications. Examples of such structures with particularly complex cross-sections include ships, which often feature, among others, several decks, a double bottom, double sides and a range of stiffeners. Understanding the dynamic behaviour of these structures has proven to be crucial, as loads due to structural vibrations can be of significant magnitude and have been suggested as the dominant cause of fatigue damage [1].

Simulation methods for the investigation of vibrations of such structures are becoming increasingly advanced, with current trends focusing on either shell modelling [2] or sophisticated beam models [3] to depict the complexity of the cross-section appropriately. The above becomes particularly significant when investigating antisymmetric vibrations, that is horizontal bending and twisting of the ship structure. In these cases, accurate modelling of the shear flow within the cross-section becomes critical, as it affects properties such as the torsional constant and the location of the shear centre. In turn, these properties affect not only the natural frequencies but also the mode shapes and modal coupling between horizontal bending and torsion [4].

Unfortunately, manufacturing scaled physical models of such complex structures can be very challenging. As a result, validation of computational methods today is predominantly based on experiments on reasonably simple structures, such as uniform U-beams [5]. Similarly, in the case of ship models for hydroelastic experiments, the structural aspect is usually introduced by means of a flexible backbone, which tends to be a uniform aluminium extrusion [6]. These extrusions, in the case of investigations on antisymmetric responses, have either a U-shaped [7] or rectangular cross-section, the latter with cut-outs to emulate deck openings [8]. The only investigation on torsion of a more ship-shaped model was performed by Sun et al. [9], using a large-scale steel model. However, the loading was quasi-static - the focus being on ultimate strength - and the structure still lacked significant internal detail, consisting of an external shell with large deck openings and transverse bulkheads. Consequently, experimental results for vibration of structures with a complex cross-section, that would be particularly useful for validation of computational methods, are absent from the literature.

3D printing could be a way to produce more detailed thin-walled structures for experimental use. This method, however, introduces its own challenges. The mechanical properties of the material, if provided by the manufacturer, are often derived from testing on the bulk material rather than its final manufactured form. Even in the cases where tests on 3D printed coupons have been performed, these refer to quasi-static (tensile or bending) tests of coupons with a particular infill ratio. Furthermore, a large number of parameters, such as the printer model, extrusion temperature, extrusion speed and layer height can significantly affect the material properties and are not necessarily mentioned in the material specification [10]. Our understanding of the mechanical properties of $3 \mathrm{D}$ printed structures is still developing and does not allow us to safely ex- 
trapolate these results to predict the performance of structures printed under different conditions.

Although the relevant scientific literature is growing, most investigations focus on the quasi-static responses and, particularly, ultimate strength of these materials (e.g. [11]). Previous work demonstrated that the flexural modulus of $3 \mathrm{D}$ printed ABS components can be substantially different if measured on a component under static or under dynamic loading [12]. Similar observations were made by Colón Quintana et al. and attributed to viscoelasticity [13]. Consequently, results from quasi-static loading of coupons, that constitute most of the current literature, are irrelevant to investigations in structural vibration.

Colón Quintana et al. performed a thorough dynamic mechanical analysis to characterise the material and identify the elastic, loss and storage moduli for various infill ratios [13]. It would be impractical for investigators to perform full material characterisation every time they are designing an experiment using a thin-walled structure. Relevant challenges would include not only potentially limited availability of the necessary equipment and/or expertise to perform such an investigation but also the substantial testing time associated with it. The relevant time investment could be comparable to the duration of the entire design and production process. It can also be argued that a significant part of the results would not be in any way relevant to design of a thin-walled structure, such as a scaled model of a container ship. The area of interest, in this case, is limited to the "effective" flexural and shear moduli, to the extent that they affect the natural frequencies of the structure. Estimation of the damping properties of the material during the design stage would also be an advantage but is not, in most cases, a straightforward process.

In this investigation, a specimen-scale method was developed to be used during the design stage of $3 \mathrm{D}$ printed thin-walled structures. This method was designed to use readily available equipment and techniques to derive the material properties that affect the natural frequencies of such a structure. To be specific, results from modal testing experiments were combined with finite element modelling techniques to identify the effective flexural and shear moduli of 3D printed specimens with a cellular (box-shaped) cross section. It was also demonstrated that quasi-static tests are inappropriate for the determination of these material properties. These values were then used to predict the natural frequencies of a much more complex cellular structure, the cross section of which resembled that of a container ship. In all cases, the material was modelled as isotropic to minimise the number of material tests necessary. The method's predictions were evaluated against results from modal testing of the uniform container ship. Measured values of structural damping for the specimens and container ship were also compared.

\section{Specimen production, testing and modelling}

\subsection{Cellular specimen production}

For the purposes of this investigation, specimens of a constant, hollow rectangular cross section were manufactured using $3 \mathrm{D}$ printing. The test points 
are depicted in Figure 1. The geometry of the cross-section was based on the cellular structure of the container ship, as highlighted in Figure 4. ABS was printed in an UP box printer with an infill ratio of $99 \%$, resulting in almost entirely solid structure. The layering direction was the same for all specimens and parallel to their longitudinal axis, so that the layer planes were parallel to the cross section. Specimens of four different lengths were manufactured, namely $180 \mathrm{~mm}, 260 \mathrm{~mm}, 390 \mathrm{~mm}$ and $520 \mathrm{~mm}$. Details regarding the cross section are summarised in Table 1.

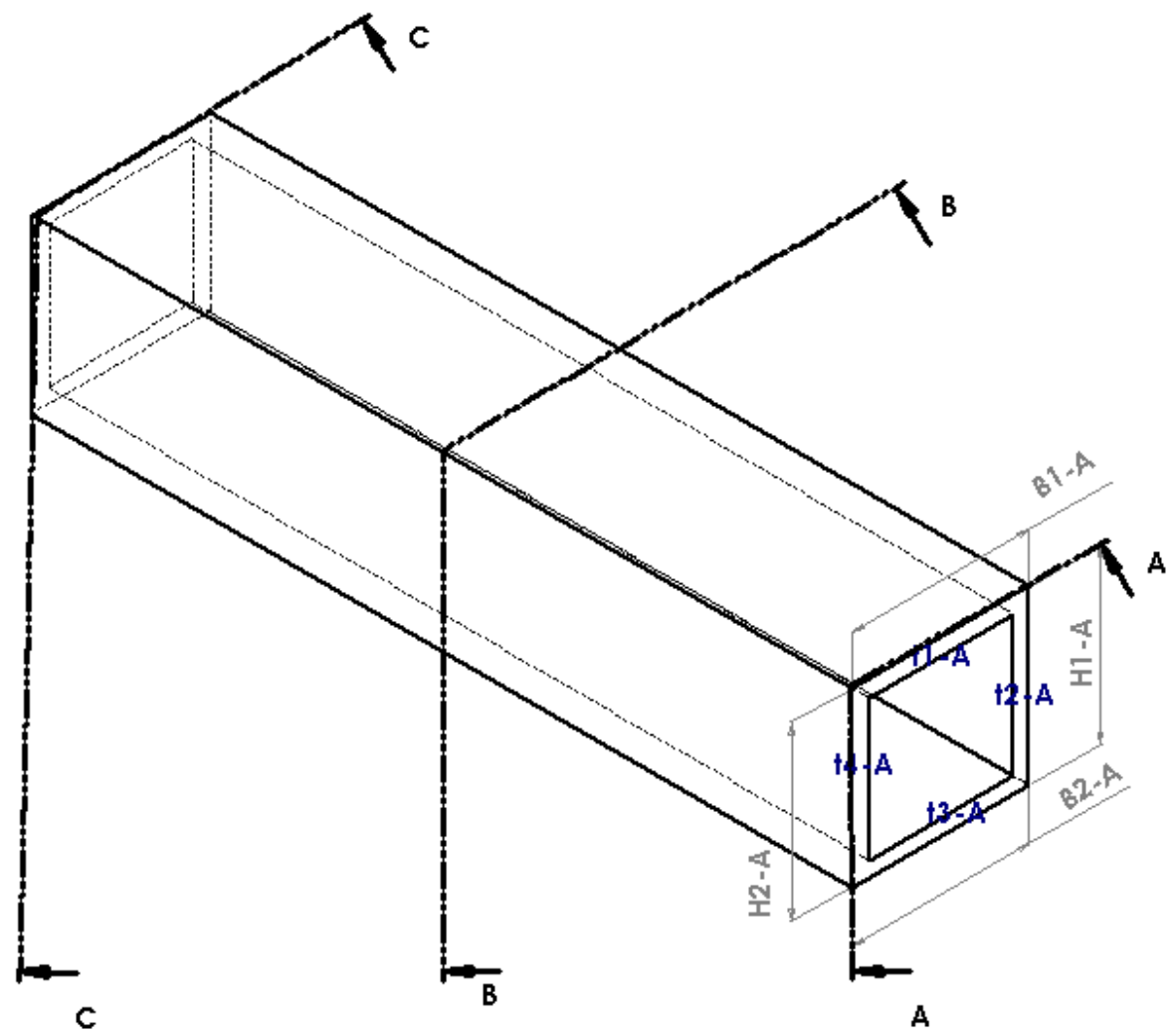

Figure 1: Depiction of the test points for each specimen segment. A, B and C denote the 3 sections where measurements were obtained. H, B and t represent measurements of height, breadth and thickness, respectively. No thickness measurements were obtained at the midpoint.

In the case of $180 \mathrm{~mm}$ specimens, both a continuous version and a version of two equal segments joined in the middle were produced. The remaining specimens were all produced in segments of $130 \mathrm{~mm}$. In all cases, the segments were joined together using a solution of ABS (the same as the one used for printing) in acetone. The segments were constrained together using sash clamps while the acetone was evaporating to leave just ABS in the area of connection. 
Table 1: Specimen cross section details, with mean and standard deviation calculated for the entire population of specimens, rather than each specimen type separately (see Table 2).

\begin{tabular}{ccc}
\hline Dimension & Mean & SD \\
\hline Breadth $(\mathrm{m})$ & 0.0280 & $9.88 \mathrm{E}-05$ \\
Height $(\mathrm{m})$ & 0.0273 & $7.62 \mathrm{E}-05$ \\
Thickness $(\mathrm{m})$ & $2.67 \mathrm{E}-03$ & $6.31 \mathrm{E}-05$ \\
Cross-sectional Area $\left(\mathrm{m}^{2}\right)$ & $2.68 \mathrm{E}-04$ & $1.40 \mathrm{E}-06$ \\
$2^{\text {nd }}$ Moment of Area $\left(\mathrm{m}^{4}\right)$ & $2.76 \mathrm{E}-08$ & $1.52 \mathrm{E}-10$ \\
Torsional constant $\left(\mathrm{m}^{4}\right)$ & $4.45 \mathrm{E}-08$ & $2.27 \mathrm{E}-10$ \\
Warping constant $\left(\mathrm{m}^{6}\right)$ & $1.25 \mathrm{E}-14$ & $4.47 \mathrm{E}-16$ \\
Mass/ Unit Length $(\mathrm{kg} / \mathrm{m})$ & 0.2622 & 0.0067 \\
\hline
\end{tabular}

Table 2: Specimen type length, number of segments, number of specimens tested and number of test points used per specimen.

\begin{tabular}{|c|c|c|c|c|c|}
\hline \multirow[t]{2}{*}{$\begin{array}{c}\text { Specimen } \\
\text { Type }\end{array}$} & \multicolumn{2}{|c|}{$\begin{array}{l}\text { Length } \\
(\mathrm{m})\end{array}$} & \multirow[t]{2}{*}{ 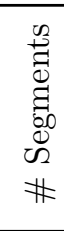 } & \multirow[t]{2}{*}{ 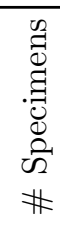 } & \multirow[t]{2}{*}{ 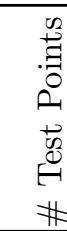 } \\
\hline & Mean & $\mathrm{SD}$ & & & \\
\hline $\mathrm{A}^{*}$ & 0.180 & & 1 & 5 & 3 \\
\hline B & 0.180 & $1.21 \mathrm{E}-04$ & 2 & 5 & 3 \\
\hline $\mathrm{C}$ & 0.256 & $1.00 \mathrm{E}-04$ & 2 & 6 & 5 \\
\hline $\mathrm{D}^{\dagger}$ & 0.260 & $9.77 \mathrm{E}-05$ & 2 & 5 & 5 \\
\hline $\mathrm{E}$ & 0.390 & $4.41 \mathrm{E}-04$ & 3 & 5 & 8 \\
\hline $\mathrm{F}$ & 0.520 & $1.45 \mathrm{E}-04$ & 4 & 3 & 11 \\
\hline
\end{tabular}

${ }^{*}$ Only nominal length available
${ }^{\dagger}$ Including transverse bulkheads

An alternative version of the $260 \mathrm{~mm}$ specimens, including bulkheads at the ends and the middle of the specimen, was also produced. A summary of all specimen designs is presented in Table 2 .

Extensive measurements were taken on each specimen segment prior to joining. Four thickness measurements, two breadth measurements and two height measurements were taken on each end of the segment. Two additional breadth and height measurements were taken at the midpoint of each specimen. The measurements were used to calculate the cross-sectional area and second moment of area at different points of each specimen. An average value was then used for each of the specimens.

\subsection{Specimen modal testing}

The specimens were subjected to modal testing with both ends treated as free supports. They were tethered using flexible bands at the nodal locations of 
the 2-node bending mode, to minimise the influence of support on the aforementioned mode $[14,15]$, which was the main focus of the investigation. The roving hammer setup used a PCB-086E80 instrumented hammer (sensitivity: $( \pm 20 \%)$ $22.5 \mathrm{mV} / \mathrm{N}$ ) for the excitation measurement and a PCB-352C22 accelerometer (sensitivity: $( \pm 15 \%) 1.014 \mathrm{mV} /\left(\mathrm{m} / \mathrm{s}^{2}\right)$, frequency range: $( \pm 5 \%) 1.0$ to 10000 $\mathrm{Hz}$ ), located at one of the free ends of the specimen, for the response measurement. Both measurements were obtained using a DataPhysics Quattro Dynamic Signal Analyzer and SignalCalc software and the latter was also used for the calculation of the relevant frequency response functions.

The mass of the accelerometer was sufficiently small $(0.5 \mathrm{~g})$ to not affect the dynamic responses of the specimens. The cables were also very lightweight and were supported without being taut, so as to minimise adding mass, stiffness or damping to the system.

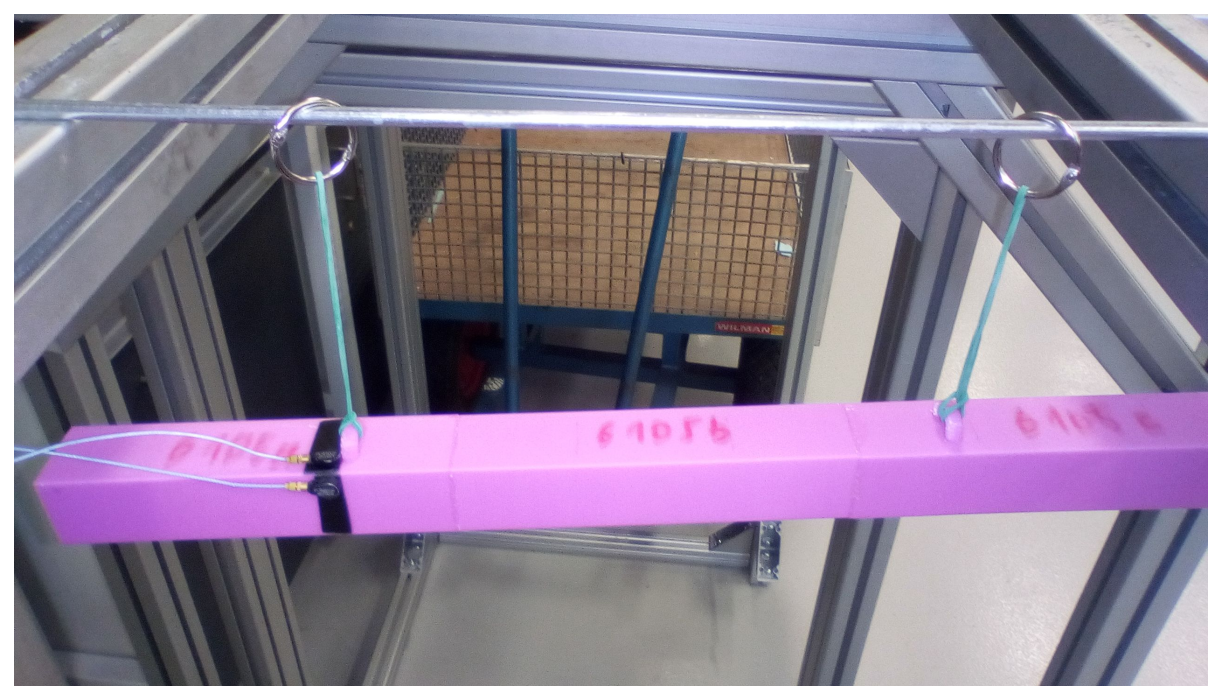

Figure 2: Specimens were tested in antisymmetric vibration using two accelerometers, in the transverse and vertical direction, respectively.

5 specimens were tested for most specimen types (with two exceptions) and the number of test points increased with the length of the specimen. Details about numbers of specimens and test points, which were approximately evenly distributed along the length, are found in Table 2. For each test point, the test was repeated thrice, the frequency response function was calculated for each repetition and an average was produced. The measured frequency range was between 0 and $2000 \mathrm{~Hz}$ (at a $0.5 \mathrm{~Hz}$ step), thus including the 2-node bending natural frequency for all lengths (see Table 2), and higher natural frequencies for the longer specimens.

The natural frequencies of the vessel were obtained from the modal test results by identifying peaks in the magnitude of the frequency response function combined with rapid change in the phase. Both the experimental procedure 
and the post-processing method described above were based on the relevant ASTM standard [16], with an increased number of test points. Adjustments were made in the post-processing of results to account for differences in the specimen geometry compared to what is prescribed. Furthermore, the specimens were modelled not only analytically but also using FEA methods, as will be discussed in more detail later.

3 specimens of specimen type B (390 mm long) were also tested in torsion to identify the shear modulus. For the purposes of this investigation, two accelerometers were used, installed on the top and side wall of the specimen. Both accelerometers were installed at one of the two-node bending mode nodes, to minimise the effects of 2-node bending on the response (see Figure 2). The supports were, once more, placed at the 2-node bending mode nodes and could potentially introduce a small interference in the torsional responses. However, this did not seem to hinder the predictive capabilities of the method, as will be demonstrated by the accurate calculation of the antisymmetric natural frequencies of the vessel in section $4 \mathrm{~A}$ vertical impact excitation was applied, this time at points off the centreline and at the opposite side (transversely) from the accelerometers. The same test points along the length of the specimen as in vertical excitation cases were used.

\subsection{Specimen 3-point bending testing}

The shorter specimen types (A, B, C, D) were also subjected to 3-point bending tests. A servo-mechanical INSTRON testing machine was used for this purpose. Specimen types $\mathrm{E}$ and $\mathrm{F}$ were not subjected to this type of testing due to maximum length restrictions. The specimens were supported by two circular rollers at $10 \%$ of the length from either end, emulating pinned-pinned boundary conditions. Both rollers had a diameter of $10 \mathrm{~mm}$. A third roller of the same size applied a displacement at the midpoint of the specimen, descending at a speed of $2 \mathrm{~mm} / \mathrm{min}$. All the above parameters were based on the standard for the determination of flexural properties of plastics [17].

\subsection{Specimen numerical modelling}

The specimen structure was then modelled using a number of different methods to investigate their validity for each specimen type. All values, including geometrical aspects, mass and experimental measurements (natural frequency, quasi-static extension \& load) were averaged per specimen type for the purposes of these calculations.

As all the specimens, with the exception of specimen type D which included bulkheads, featured a uniform cross section and uniform mass distribution, the dynamic flexural modulus may be calculated with an Euler beam approximation, namely:

$$
\omega_{2 V B}=\frac{4.73^{2}}{L^{2}} \sqrt{\frac{E I}{\mu}}
$$


where $L$ is the specimen length, $E$ the flexural modulus, $I$ the $2^{\text {nd }}$ moment of area and $\mu$ the mass per unit length.

The second modelling method used a Timoshenko beam approach (element BEAM188 in ANSYS), whereas the third method employed a fully 3D FEA approach with shell elements including both membrane and bending loads (element SHELL181 in ANSYS). In all cases, lines were meshed with a maximum element length of $0.0009 \mathrm{~m}$; that is to say, an element size of 0.0009 was used along all axes. The material was modelled as isotropic, to minimise the number of experiments necessary to identify mechanical properties in different directions. The issues associated with this assumption were minimised during production by printing both the specimens and the vessel in the same orientation. The cross-sectional properties (in the case of beam modelling) and the wall thickness (in the case of shell modelling) were selected based on the averages for each of the specimen types. The eigenvalue problem of the specimen with free-free boundary conditions was solved to compare to dynamic tests.

The models above were then modified for static simulations. This included modelling a quarter of each specimen with double symmetry conditions and adding roller support and a single applied deflection. The results were compared to the 3-point bending tests for a strain equal to 0.0025. In terms of the Euler beam approximation, the modulus was found by using the points corresponding to strain of 0.0005 and 0.0025 , as prescribed by the EN ISO standard.

\subsection{Post-processing of experimental results using numerical models}

An iterative process was followed to obtain the flexural modulus from the modal tests. An initial value for the flexural modulus was used for each of the structural models described above, to obtain the relevant prediction for the 2node bending natural frequency (or 1-node twisting in the case of antisymmetric excitation). This prediction would then be compared to the average natural frequency measured for the specimen type in question during the experiments. Based on this comparison, a new estimation of the flexural (or shear) modulus was produced for each of the structural models and the process was iterated until the predicted natural frequencies matched the measured natural frequencies.

\subsection{Calculated effective flexural and shear modulus}

The average 2-node vertical bending (or 1-node twisting, where appropriate) natural frequencies for the various specimen types are given in Table 3. Differences in natural frequencies between specimen types A and B, which only differ in terms of presence or absence of joining, were limited. More significant difference was observed between specimen types $\mathrm{C}$ and $\mathrm{D}$, which have the same length but transverse bulkheads were included in the latter. Although the bulkheads don't affect the longitudinal stiffness, they act as point masses at the local extrema of the 2-node bending mode shape (free ends and midpoint).

Strain measurements from the 3 -point bending tests are summarised in Table 4. The standard deviation in these tests was found to be more significant than the one observed in the modal tests. 
Table 3: Specimen type measured 2-node bending natural frequency $\left(\mathrm{f}_{2 \mathrm{VB}}\right)$

and 1-node twisting natural frequency $\left(\mathrm{f}_{1 \mathrm{~T}}\right)$, as measured in modal tests.

\begin{tabular}{ccccc}
\hline $\begin{array}{c}\text { Specimen } \\
\text { Type }\end{array}$ & \multicolumn{2}{c}{$\begin{array}{c}\mathrm{f}_{2 \mathrm{VB}} \\
(\mathrm{Hz})\end{array}$} & \multicolumn{2}{c}{$\mathrm{f}_{1 \mathrm{~T}}$} \\
& Mean & SD & Mean & SD \\
\hline A & 1372.47 & 22.43 & & \\
$\mathrm{~B}$ & 1381.53 & 9.52 & & \\
$\mathrm{C}$ & 737.17 & 7.72 & & \\
$\mathrm{D}$ & 678.60 & 3.33 & & \\
$\mathrm{E}$ & 340.46 & 2.93 & 1067.17 & 7.97 \\
$\mathrm{~F}$ & 194.33 & 0.90 & & \\
\hline
\end{tabular}

Table 4: Measured difference in load values corresponding to strains of 0.0025 and 0.0005 (3-point bending tests) for all specimen types subjected to 3-point bending tests.

\begin{tabular}{ccc}
\hline $\begin{array}{c}\text { Specimen } \\
\text { Type }\end{array}$ & \multicolumn{2}{c}{$\Delta \mathrm{F}_{\epsilon}=0.0005,0.0025$} \\
& Mean & $\mathrm{SD}$ \\
\hline $\mathrm{A}$ & 124.82 & 6.75 \\
$\mathrm{~B}$ & 93.51 & 17.67 \\
$\mathrm{C}$ & 99.90 & 21.71 \\
$\mathrm{D}$ & 109.65 & 5.58 \\
\hline
\end{tabular}

A summary of the dynamic flexural modulus required to match the measured natural frequency for each structural model is shown in Figure 3b. It was observed that the shell element model provides a consistent estimation of the dynamic flexural modulus (2.155 MPa with a standard deviation of $0.8 \%$ ) over all specimen types. As this model includes both shear deformation effects in bending and section warping, it was considered the most general model and was used as a baseline.

Estimations using the Timoshenko beam model were fairly close to the shell estimations (maximum difference of $3.5 \%$ ) for most specimens, with the difference between the two increasing as specimens became shorter. This difference was attributed to warping of the cross section. Warping became less apparent in longer specimens and from type $\mathrm{C}$ onwards the dynamic flexural modulus calculated using the Timoshenko beam approximation was different from the one produced with shell modelling by only $0.9 \%$.

Estimations based on the Euler-Bernoulli beam approximation diverged much more significantly for shorter specimens. For the more slender specimens with a length of $520 \mathrm{~mm}$ the difference in calculated modulus from the shell element estimation was of the order of $5 \%$. However, the difference rapidly increased with decreasing length, reaching $40 \%$ for the $180 \mathrm{~mm}$ specimens. It was evident that, for this scale of specimens, the 2-node bending natural frequency was 


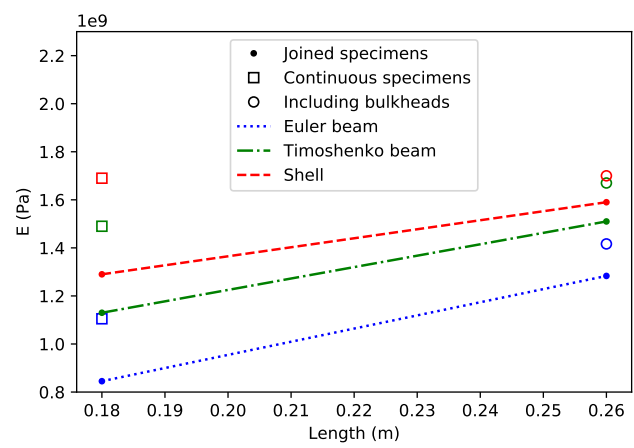

(a) Static flexural modulus

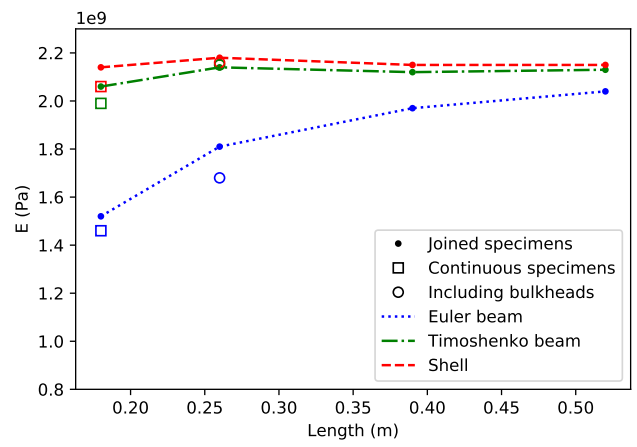

(b) Dynamic flexural modulus

Figure 3: Static and dynamic flexural moduli of the specimens, derived from the reaction force at the midpoind and the 2-node bending natural frequency, respectively, using three different structural models, as a function of specimen length. Lines (dot markers) depict specimens with no bulkheads, produced by joining a number of segments (see Table 2). Square markers depict specimens without any joining, whereas circular markers depict specimens including bulkheads.

significantly affected by shear deformation effects. Use of the Euler-Bernoulli beam approximation would only be recommended for the $520 \mathrm{~mm}$ specimens. This corresponded to a length/height ratio of 19 , which was close to the ratio of 20 recommended by the standards (for beams with a rectangular rather than box-shaped cross section) [16] to use the Euler beam approximation.

The continuous specimens (i.e. specimen type A) showed similar trends to the joined beams regarding the accuracy of the various approximations. When compared to specimen type B, comprising two segments, a slight increase in stiffness was observed, the magnitude of which was, however, comparable to the standard deviation of the measurement. As only one design without joining was tested, the evidence was deemed insufficient to draw any definite conclusions. The presence of bulkheads in specimen type D had two distinct effects. Firstly, the difference of the Euler beam results when compared to specimen type C 
signified the importance of the mass distribution when calculating the natural frequency of these structures. Secondly, being the only specimen type where the Timoshenko beam and shell models coincided, it was emphasised that bulkheads prevent any deflection of the cross section and result in a structure that can be described just as well using a beam approximation.

Measurements from antisymmetric testing of type E specimens produced an average 1-node twisting natural frequency of $1067.17 \mathrm{~Hz}$ with a standard deviation of $7.97 \mathrm{~Hz}$. Using the same iterative method as before, BEAM188 and SHELL181 elements produced a shear modulus of $841 \mathrm{MPa}$ and $881 \mathrm{MPa}$ and a Poisson's ratio of 0.26 and 0.22 , respectively.

The calculated values of static flexural modulus are summarised in Figure 3a. It can be observed that the trends for these quasi-static tests resembles the one previously discussed for the dynamic tests. However, the quasi-static flexural modulus was approximately $35 \%$ lower than its dynamic counterpart. It was concluded that viscoelastic effects cannot be ignored and identification of the quasi-static modulus would not be sufficient for the modelling of 3D printed structures which are subjected to dynamic loads.

\section{Uniform container ship production, testing and modelling}

\subsection{Uniform container ship production}

The vessel was produced using ABS with an infill ratio of $99 \%$. A uniform thickness of $2.5 \mathrm{~mm}$ was used for all longitudinal parts of the structure, which was considered to be very close to the minimum thickness the UP box could print with reasonable accuracy. The size of the deck openings and the dimensional proportions of the structure were based on the S175 container ship [18] and the cellular arrangement was inspired by real container ships (Figure 4). Each section (total of 11) was built with the longitudinal axis (x-axis) of the vessel coinciding with the z-axis (the layering direction) of the printer. A $4 \mathrm{~mm}$ deep frame marked the start of each section, and appropriate slots at the beginning and end of each section ensured that this thickness was shared equally between two subsequent sections (Figure 5). The remaining middle part of the section was prismatic. 10 of the sections were printed with a length of $140 \mathrm{~mm}$ whereas the fore section had a length of $120 \mathrm{~mm}$ to achieve the required length of 1.52 $\mathrm{m}$.

The sections were joined using an ABS paste made with scrap pieces of the parent material dissolved in acetone (the same as the one used for the specimens). The large size of the prints combined with the high thermal expansion rate of ABS resulted in slight peeling of the corners of the section off the print bed and subsequent curving of the bottom of the print. This was resolved by application of the aforementioned paste to fill the gaps during the joining process. As the longitudinal parts of the cross section were practically solid and the paste solidifies into ABS after acetone evaporates, this practice intended to produce similar properties and ensure longitudinal continuity. A series of bulkheads were added at the same locations as the deep frames, excluding three 


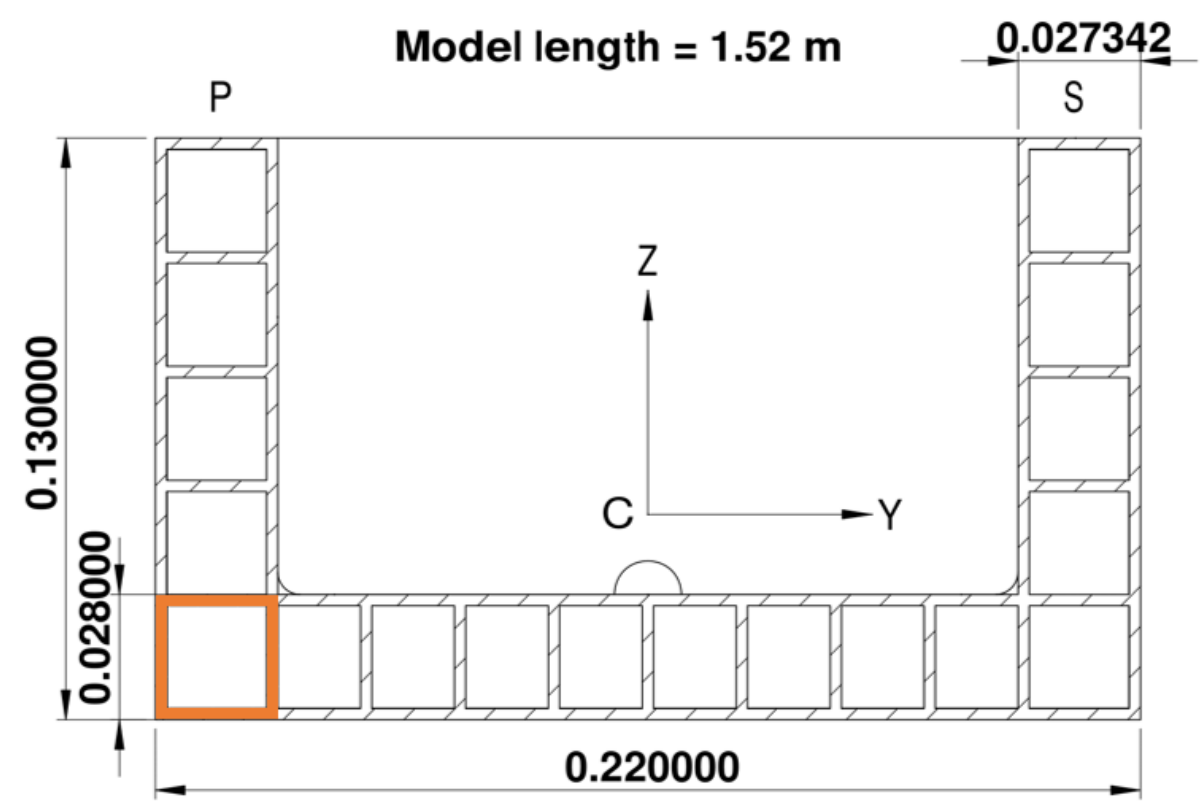

Figure 4: Dimensions of the cross-section of the barge were based on a scaled-down version of the S175 container ship [18]. X-axis, Y-axis and Z-axis correspond to the directions accros the length, breadth and depth of the container ship, respectively. The highlighted square at the bottom left corner corresponds to the cross section of the specimens.

deep frames where their installation was impossible because of the presence of sensors and attachments relevant to other experiments.

As the structure corresponded to a ship, the location along the longitudinal direction was defined by use of stations. Within this convention, station 0 corresponded to the stern of the vessel and station 20 corresponded to the bow. Any station in between corresponded to its number times $5 \%$ of the length, measured from the stern - for example, station 15 corresponded to $15 \times 5 \%=$ $75 \% \mathrm{~L}$, measured from the stern. In terms of locations within the cross section, main deck refers to the horizontal plating at the top of the structure, on either side; side wall refers to the external vertical plating, whereas inner side refers to the internal vertical walls. Port and starboard are the nautical terms for the left and right side of the vessel, respectively.

\subsection{Uniform container ship cross-sectional properties}

Dimensional measurements were taken throughout the sections of the structure and compared to nominal values. It was observed that uncertainties were much more pronounced for thickness as opposed to larger dimensions. In most cases, thickness average was found to be 10-23\% higher from the nominal but with a standard deviation of $1.5-4.3 \%$ of the average value. Smaller deviations were previously observed for the thickness of specimens (3-16\% higher than 


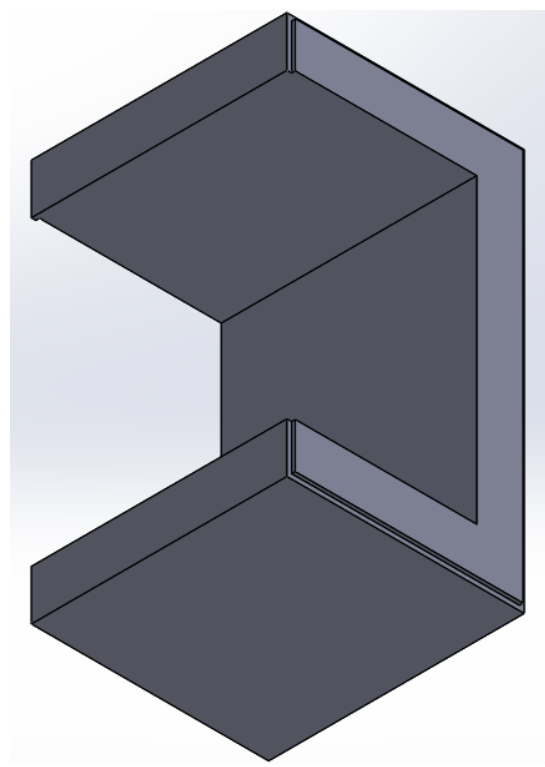

(a) Section (shaded)

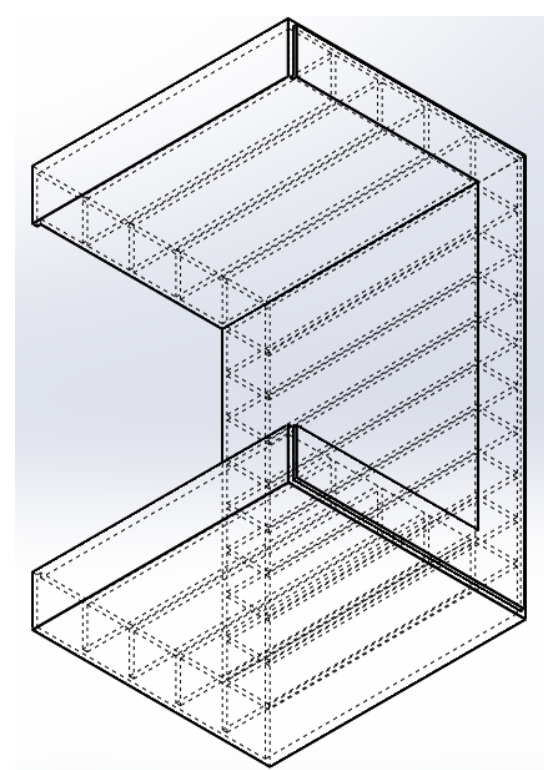

(b) Section (X-ray)

Figure 5: CAD representation of one of the sections of the model. The deep frame (including a slot to allow easy assembly) is clearly visible in (a), whereas the internal cellular geomery is shown in (b).

nominal). The maximum values for error and standard deviation for the larger dimensions were $1.08 \%$ of the nominal value and $0.38 \%$ of the average, respectively. The final length of the vessel was found to be $1.525 \mathrm{~m}$, which results in an error of $0.3 \%$.

The geometric inaccuracies described above were a result of an older-generation $3 \mathrm{D}$ printer being used for the purposes of the project, which was struggling to produce this level of thickness. Currently available printers would not suffer from these issues and would, in fact, be able to accurately produce structures with a thickness of less than $1 \mathrm{~mm}$. It should be noted that the aforementioned issue of the geometrical inaccuracies has no impact on the validity of the proposed methodology and its results.

The mean values and standard deviation of various dimensional measurements of the cross section were used as an input to a Monte-Carlo simulation to evaluate the uncertainty over cross-sectional properties. A population of 10000 randomly-generated cross sections was used and results were found to converge after approximately 1000 sections. A summary of the results can be found in Table 5. It was concluded that the variation of cross-sectional properties, particularly in terms of the cross-sectional area and 2nd moment of area, is not large enough to affect the estimation of vibratory properties of the vessel. The average values from the Monte Carlo simulation were used during the vessel modelling with finite elements (see 3.4). 
Table 5: Statistical predictions for the cross-sectional properties of the vessel, based on dimensional measurements and use of a Monte-Carlo simulation. The $2^{\text {nd }}$ moment of area was calculated around the transverse axis at the level of the centroid.

\begin{tabular}{ccc}
\hline Property & Mean & SD \\
\hline Cross-sectional Area $\left(\mathrm{m}^{2}\right)$ & $3.72 \mathrm{E}-03$ & $3.70 \mathrm{E}-05$ \\
$2^{\text {nd }}$ Moment of Area $\left(\mathrm{m}^{4}\right)$ & $6.10 \mathrm{E}-06$ & $6.16 \mathrm{E}-08$ \\
Centroid (vertical) $(\mathrm{m})$ & $4.59 \mathrm{E}-02$ & $3.33 \mathrm{E}-04$ \\
\hline
\end{tabular}

The resulting bending stiffness of the model was higher than what is common for container ships of this size. This difference was a result, among others, of the limitations in terms of minimum thickness that could be printed. It was, however, deemed irrelevant to the purposes of this investigation, which focused on the feasibility of predicting the natural frequencies of such a complex structure, rather than the accurate depiction of a particular ship.

\subsection{Uniform container ship testing}

The container ship was also subjected to modal testing at a free support condition. It was tethered using bungee cords at stations 6 and 14 (Figure 6), as due to spacial constraints in the experimental setup it was not possible to tether it exactly at the 2 -node vertical bending mode nodes (namely stations 5 and 15). The roving hammer setup used a PCB-086C03 instrumented hammer (sensitivity: $( \pm 15 \%) 11.2 \mathrm{mV} / \mathrm{N})$ with a hard plastic tip (white) for the excitation measurement and three PCB-352C22 accelerometers (sensitivity: $( \pm 15 \%)$ $1.019 \mathrm{mV} /\left(\mathrm{m} / \mathrm{s}^{2}\right), 0.998 \mathrm{mV} /\left(\mathrm{m} / \mathrm{s}^{2}\right)$ and $1.003 \mathrm{mV} /\left(\mathrm{m} / \mathrm{s}^{2}\right)$, respectively) for the response measurement. The difference in the hammer model, compared to specimen testing, was due to the need for a bigger hammer to excite the structure of the container ship.

The accelerometers were located at station 19 of the container ship on the starboard side. Two of them were installed on the inner side to measure along the Y-axis, that is the transverse axis of the container ship. This setup was selected so that further post-processing of the measurements would allow the calculation of translational (along the transverse direction) and rotational (along the longitudinal direction) acceleration at the midpoint [15]. The vertical locations of these accelerometers $(\mathrm{z}=0.031$ and 0.059 from the bottom, respectively) were selected so that the midpoint coincides with the vertical location of the centroid of the cross-section. The third accelerometer was placed on the main deck to measure along the vertical direction. In summary, the translational accelerations along the breadth and depth of the ship and the rotational acceleration along the length of the ship were measured.

All measurements were obtained using a DataPhysics Quattro acquisition system and SignalCalc software and the latter was also used for the calculation of the relevant frequency response functions. For each test point, the test was repeated thrice, the frequency response function was calculated for each repetition and an average was produced. The measured frequency range was between 


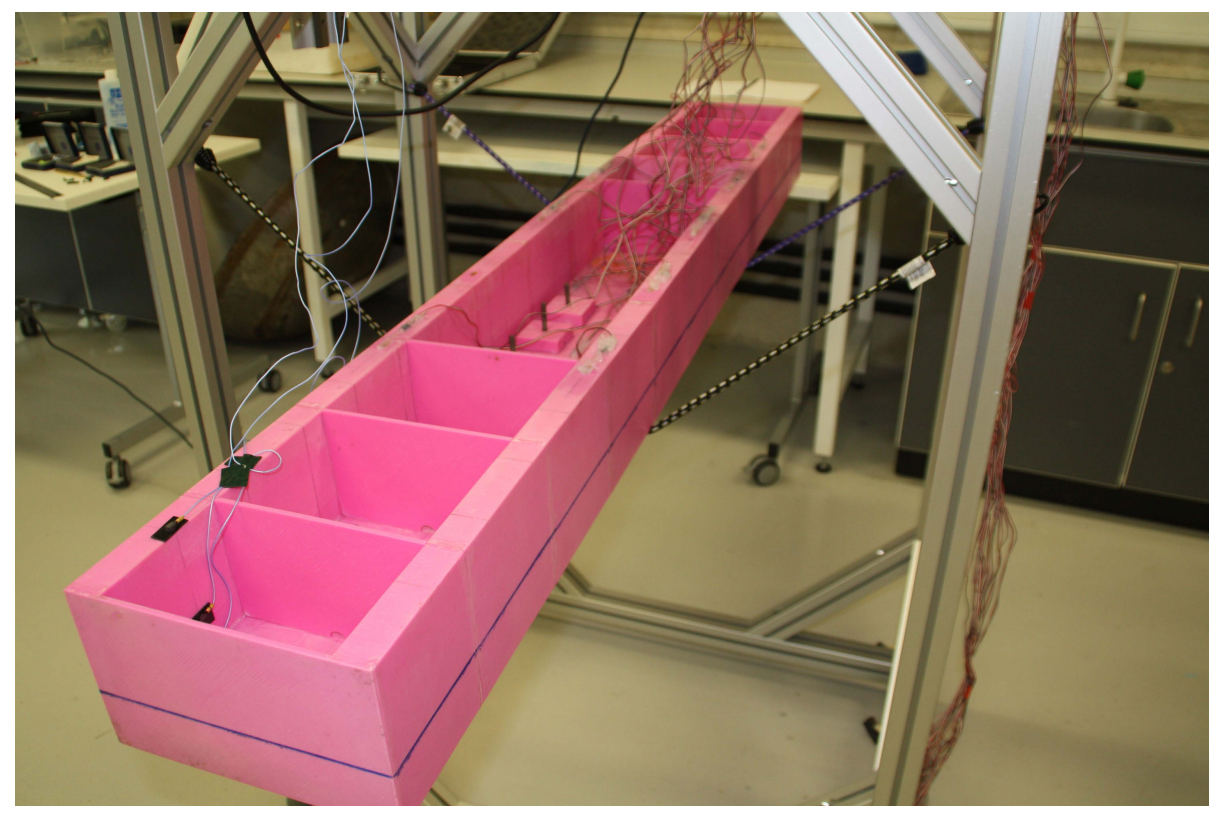

Figure 6: The container ship model was suspended using bungee cords at stations 6 and 14 to emulate a free boundary condition. This support arrangement was not changed for measurement of different modes and was used to measure both symmetric and antisymmetric responses.

0 and $400 \mathrm{~Hz}$ (at a $0.5 \mathrm{~Hz}$ step), as this was expected to contain at least the 6 first modes of the vessel.

The container ship testing was split into two phases. In the first one, the container ship was excited horizontally. The excitation points were located at each station (so every $5 \%$ of the container ship length), starting at station 1 and ending at station 19. For all stations, the excitation point was located at the side wall of the container ship at the corner with the main deck. Measurements were obtained on both the port and the starboard side.

In the second phase, the container ship was excited vertically. The excitation points were located at the midpoint of the main deck plates (i.e. halfway between the inner skin and outer skin, see location of letters P and S in Figure 4), both for port and starboard side. In this case, not all stations could be excited due to the presence of strain gauges installed for other tests, preventing access to stations $4,5,7,9,10,12,15$ and 18 . The access in these cases was obstructed by the presence of either strain gauges or relevant cables at the station (see also Figure 6). Stations 1, 2, 3, 6, 8, 11, 13, 14, 16, 17 and 19 were excited on both sides of the vessel. These corresponded to longitudinal locations at $5 \%, 10 \%$, $15 \%, 30 \%, 40 \%, 55 \%, 65 \%, 70 \%, 80 \%, 85 \%$ and $95 \%$ of the model length. 


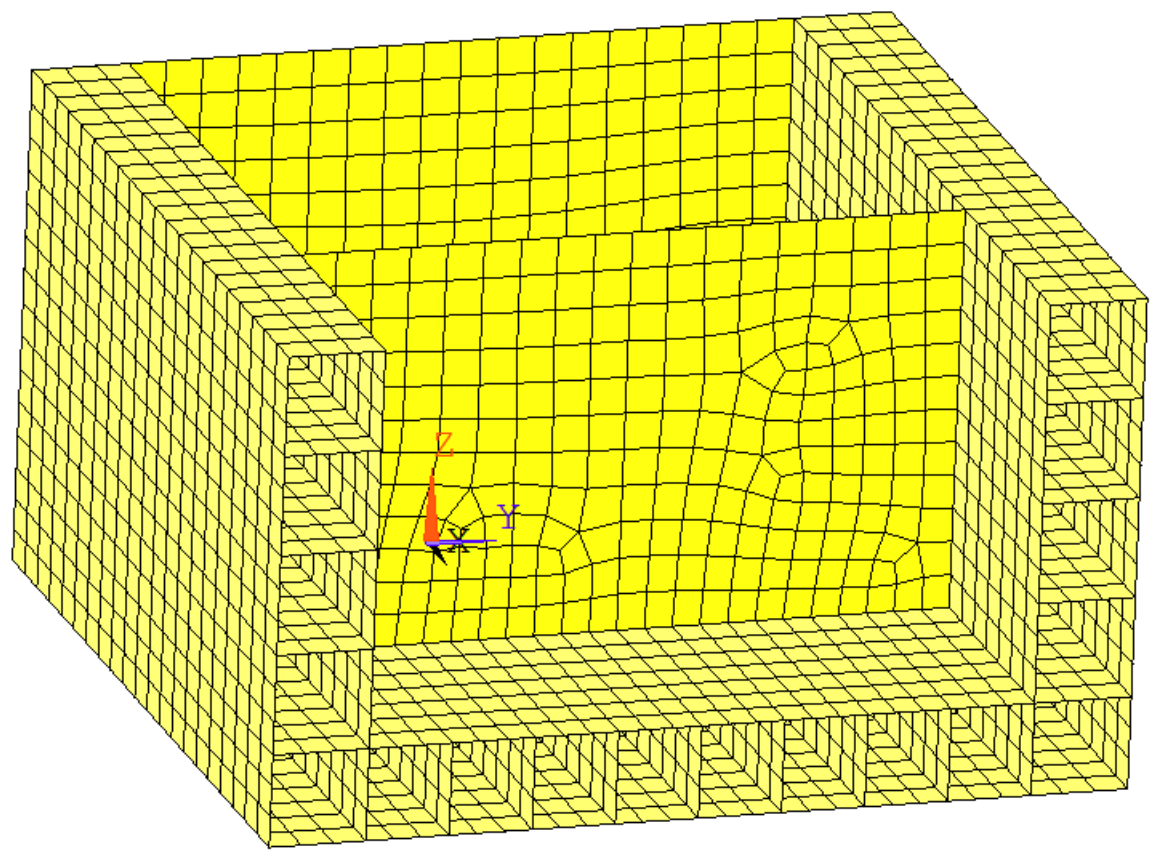

Figure 7: The mesh size resulted in the width of each bulkhead corresponding to 18 elements and the width of each deck strip(port and starboard) corresponding to 3 elements. Looking at the cross-section, each wall of any cell of the cellular structure corresponded to 3 elements. The distance between two consecutive deep frames corresponded to 14 elements.

\subsection{Container ship modelling}

The vessel was modelled using element SHELL181.The cross section was designed in 2D and extruded, and the transverse bulkheads and deep frames were also included. In all cases, lines were meshed with a maximum element length of $0.01 \mathrm{~m}$ (Figure 7 . The material was, once more, modelled as isotropic. The flexural modulus that was obtained from testing the longest specimens (Type F), as derived from shell modelling, was used. The Poisson's ratio corresponding to shell modelling of the specimens was used.

\section{Natural frequencies and mode shapes of the container ship}

The natural frequencies of the vessel were obtained from the modal test results by identifying peaks in the magnitude of the frequency response function combined with rapid change in the phase. The relevant mode shapes were obtained by plotting the imaginary part of the response, for each of those frequencies, for the various excitation points. A comparison between the vessel's natural frequencies, as predicted by ANSYS and as measured experimentally is presented in Table 6 . 
Table 6: Unballasted vessel natural frequencies, as predicted by ANSYS and as measured experimentally. $\mathrm{HB}, \mathrm{VB}$ and $\mathrm{T}$ denote horizontal bending, vertical bending and torsion, respectively, whereas the numbers preceding them denote the number of nodes in the mode shape.

\begin{tabular}{cccc}
\hline \multirow{2}{*}{ Mode } & \multicolumn{2}{c}{ Frequency $(\mathrm{Hz})$} & Difference \\
& Predicted & Measured & $\%$ \\
\hline 1-HB, 1-T & 63.9 & 65.7 & -2.44 \\
2-VB & 79.0 & 75.1 & 5.33 \\
2-HB, 2-T & 100.2 & 97.5 & 2.77 \\
3-HB, 3-T & 193.1 & 191.1 & 1.10 \\
3-VB & 196.1 & 191.1 & 2.67 \\
2-HB, 2-T & 206.8 & 200.2 & 3.30 \\
4-HB, 4-T & 303.8 & 299.4 & 1.44 \\
\hline
\end{tabular}

$\dagger$ Inconclusive mode shape information

The mode shapes calculated in ANSYS can be found in Figures 8b, 8d, 8f, $8 \mathrm{~h}, 8 \mathrm{i}$ and $8 \mathrm{k}$. The corresponding operating deflections shapes (ODS) measured in the experiments can be found in Figures $8 \mathrm{a}, 8 \mathrm{c}, 8 \mathrm{e}, 8 \mathrm{~g}$ and $8 \mathrm{j}$. The ODS were not normalised and the values on the vertical axis of the graphs correspond to the imaginary part of the acceleration frequency response function, thus they are measured in $\left(\mathrm{m} / \mathrm{s}^{2}\right) / \mathrm{N}$ (translation) or $\left(\mathrm{rad} / \mathrm{s}^{2}\right) / \mathrm{N}$ (rotation).

As shown in Figures $8 \mathrm{a}, 8 \mathrm{c}, 8 \mathrm{e}, 8 \mathrm{~g}$ and $8 \mathrm{j}$, the operating deflection shapes (ODS) corresponding to the various mode shapes were calculated separately for port and starboard excitation. The results presented in Figures 8a, 8e, 8g and $8 \mathrm{j}$ correspond to horizontal excitation, whilst the result presented in Figure $8 \mathrm{c}$ corresponds to vertical excitation. It should be noted that results from either horizontal or vertical excitation denote the same modal characteristics for the ODS; nevertheless, those for symmetric and antisymmetric modes are clearer from vertical and horizontal excitation, respectively. For all antisymmetric modes, the impact was applied with a direction from the side wall towards the centreline, resulting in opposite excitation directions, therefore the operating deflection shapes resulting from the two excitation sides had opposite phase.

The results from vertical excitation are not presented as they were almost identical; in this case, opposite phases were explained based on the the antisymmetric nature of these modes. The only occasion where the port and starboard side were in phase was the 2-node vertical bending ODS (Figure 8c). This is the only case in which the results from vertical excitation are presented instead. The second symmetric mode (3-node vertical bending) is located very close to the 3-node horizontal bending - 3-node twisting mode, resulting in an operating deflection shape combining both modes (Figure 8g).

The fact that all operating deflection shapes seem to excite horizontal displacement, vertical displacement and rotation might seem confusing at first but there are a number of reasons why this was the case. Firstly, as the accelerometer measuring vertical acceleration was located on the Main deck, it would 

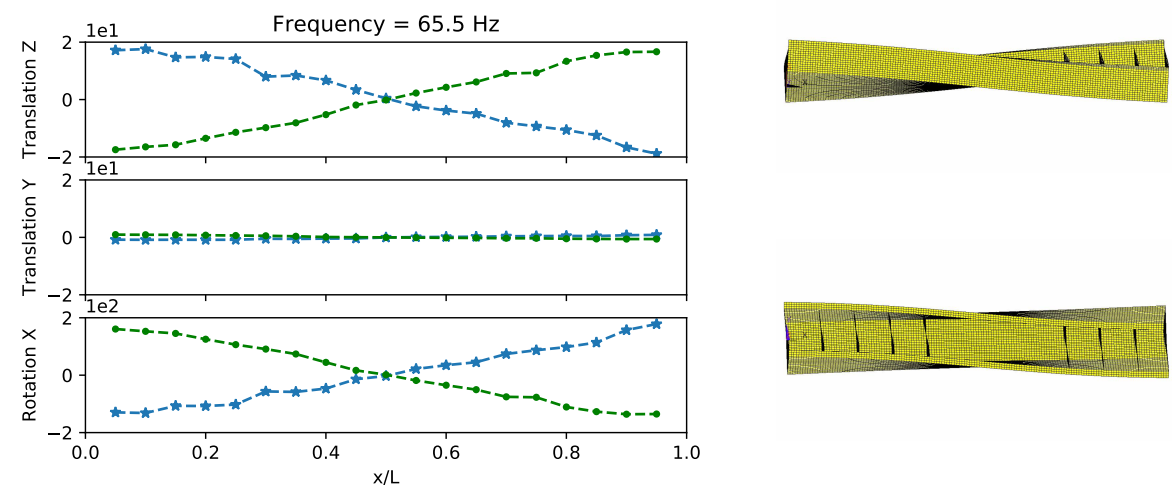

(a) Measured ODS at $65.5 \mathrm{~Hz}$

(b) Mode shape at $63.9 \mathrm{~Hz}$
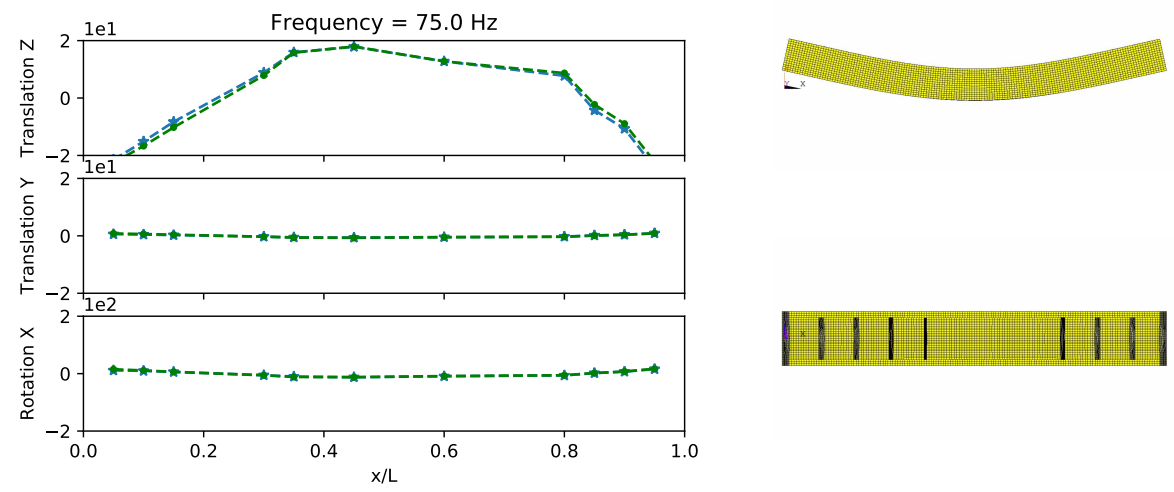

(c) Measured ODS at $75.0 \mathrm{~Hz}$

(d) Mode shape at $79.0 \mathrm{~Hz}$
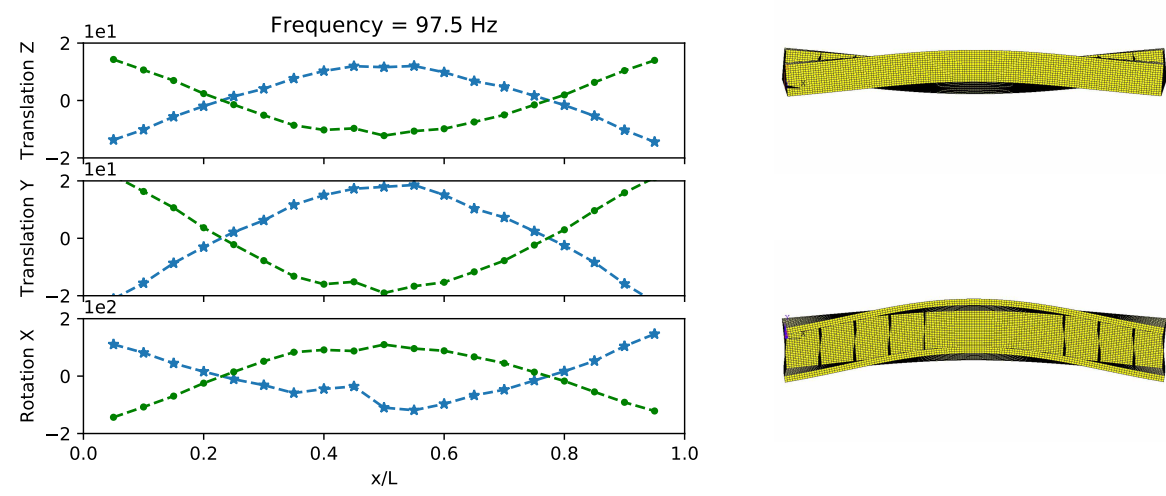

(e) Measured ODS at $97.5 \mathrm{~Hz}$

(f) Mode shape at $100.2 \mathrm{~Hz}$ 


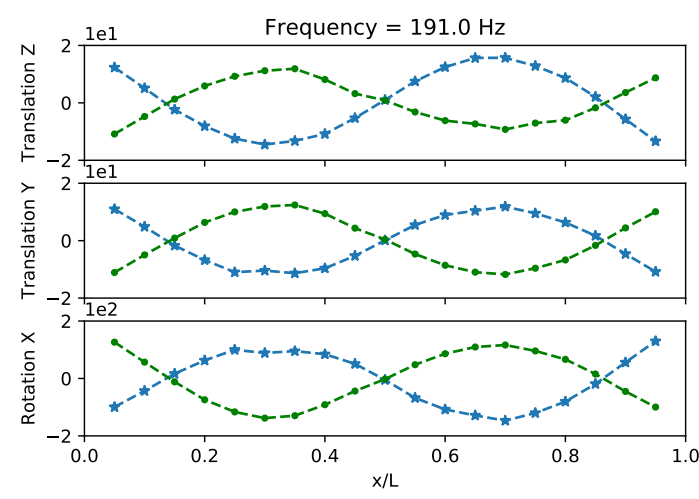

(g) Measured ODS at $191.0 \mathrm{~Hz}$

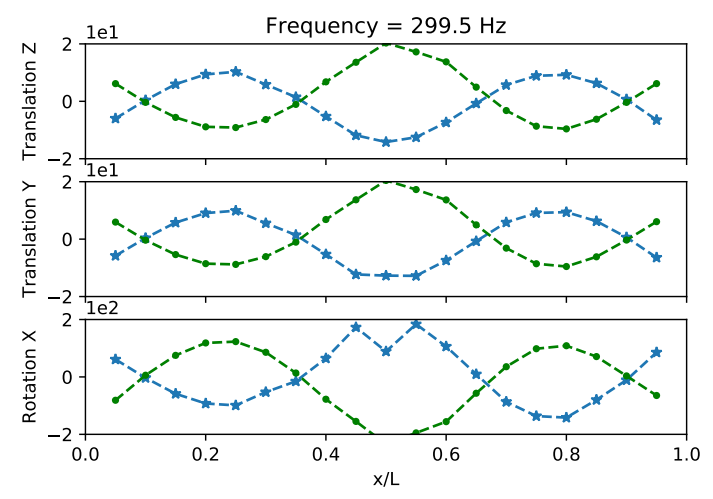

(j) Measured ODS at $299.5 \mathrm{~Hz}$

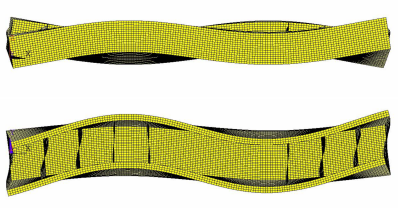

(h) Mode shape at $193.1 \mathrm{~Hz}$
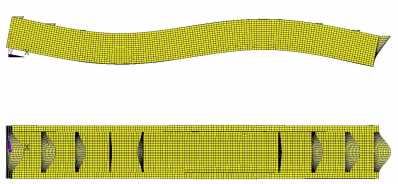

(i) Mode shape at $196.1 \mathrm{~Hz}$

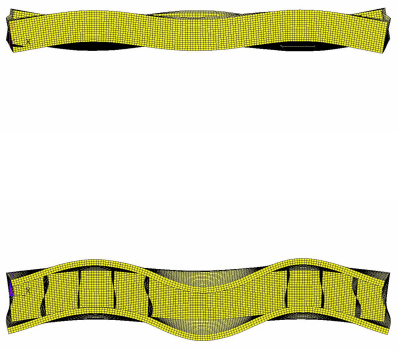

(k) Mode shape at $303.8 \mathrm{~Hz}$ )

Figure 8: The measured ODS and the corresponding mode shapes from the FEA simulations. From top to bottom: 1-node horizontal bending - 1-node twisting, 2-node vertical bending, 2node horizontal bending - 2-node twisting, 3-node vertical bending - 3-node horizontal bending - 3-node twisting, 4-node horizontal bending - 4-node twisting. Green point markers and blue star markers indicate port and starboard excitation, respectively. 
actually detect torsional modes and measure values of similar magnitude to the horizontal acceleration for antisymmetric vibration. In the sole case of pure symmetric vibration, i.e. 2-node vertical bending (Figure 8c), the ODS for horizontal acceleration was measured as 20 times smaller than that for vertical acceleration and the one for rotational acceleration was an order of magnitude smaller than in any other case.

The maximum difference between predictions and measurements of the natural frequency was just over $5 \%$ (Table 6 ). As noted earlier, the 3 -node horizontal bending - 3-node twisting mode and 3-node vertical bending modes appear to coexist in the operating deflection shape in Figure 8g. Operating deflection shape for the peak at $200.2 \mathrm{~Hz}$ provided inconclusive information. However, expectations from the simulations indicate that it probably corresponds to the second 2-node horizontal bending - 2-node twisting mode or the 3-node vertical bending mode. Either way, the difference between predicted and measured values would be within the aforementioned limits.

Mode shapes beyond the 4-node horizontal bending - 4 node twisting mode, although calculated in ANSYS, were not included here for a number of reasons. Firstly, because no modes further than that could be identified from the modal tests. Secondly, because the FEA "global" mode shapes became increasingly contaminated by "local" mode shapes including, for example, bulkhead deflection, bottom deflection or deflection of the section of the vessel that was unsupported by bulkheads. Some of these localised responses were already visible in the 3-node vertical bending mode (Figure 8i) but became more pronounced with increasing mode order.

\section{Structural damping}

In order to calculate modal damping, MATLAB function modalfit [19] was used. This function takes a frequency response function (or series of frequency response functions) as an input and uses curve-fitting techniques to translate that to a series of natural frequencies and the corresponding damping ratios and mode shapes. As can be seen from the frequency content in Figure 9, the acceleration response included contributions from more than one mode. Use of this technique ensured that the whole frequency response function, rather than isolated peaks, was taken into account when calculating damping.

Damping was calculated for each specimen type, for the first one, two or three modes. The accuracy of the method decreased significantly for higher modes, as well as natural frequencies higher than $1000 \mathrm{~Hz}$. Consequently, these results had to be ignored - their importance not being particularly significant, as these measurements would be at quite different frequencies from what was measured on the vessel.

A summary of the calculated damping ratios can be found in Figure 10 and Table 7. A number of observations were made. Firstly, the spread of measurements per frequency were found to be smaller for longer specimens and lower frequencies. Secondly, the damping ratios for the first two modes of the vessel 
were quite similar to the damping ratio corresponding to the 2-node vertical bending mode for the longer specimens $(520 \mathrm{~mm})$.

Table 7: Damping ratios for the container ship.

\begin{tabular}{ccccc}
\hline \multirow{2}{*}{ Mode } & \multicolumn{2}{c}{ Frequency $(\mathrm{Hz})$} & \multicolumn{2}{c}{ Damping ratio } \\
& Mean & SD & Mean & STD \\
\hline 1-HB, 1-T & 65.7 & 0.1 & 0.0067 & 0.0003 \\
2-VB & 75.1 & 0.3 & 0.0071 & 0.0011 \\
2-HB, 2-T & 97.5 & 0.3 & 0.0078 & 0.0010 \\
3-HB, 3-T & 191.1 & 1.5 & 0.0091 & 0.0004 \\
2-HB, 2-T & 200.2 & 0.5 & 0.0089 & 0.0011 \\
4-HB, 4-T & 299.4 & 0.4 & 0.0086 & 0.0012 \\
\hline
\end{tabular}

It was concluded that measurements of structural damping from cellular specimen tests can provide a good estimation of the relevant values on a more complicated cellular structure, when both are produced using additive manufacturing and the same material. These values can serve as indicators during the design stage but experimental measurement of damping in the final structure is necessary.

\section{Conclusions}

This investigation focussed on the design and production of elastic ship models with realistic, thin-walled structural configurations. 3D printing was suggested as a plausible manufacturing solution for the scaled models and the challenges due to limited availability of material properties were presented.

A detailed methodology was developed, using specimen-scale modal tests and FEA modelling to identify the material properties that are relevant to vibratory responses of $3 \mathrm{D}$ printed structures. This is a viable and practical alternative to a full characterisation of $3 \mathrm{D}$ printed materials and is suitable for incorporation in a typical design procedure of $3 \mathrm{D}$ printed structures. It was demonstrated that the procedure can be used to accurately predict the natural frequencies of a complex thin-walled structure. Furthermore, accurate estimates regarding structural damping could also be drawn from the same measurements, especially for low natural frequencies. It was also clearly shown that use of more "traditional" 3-point bending tests would be inappropriate for the purposes of determining vibratory properties.

Use of an isotropic material model within the FEA simulations did not seem to affect the accuracy of the predictions for the container ship, despite the inherently orthotropic nature of 3D printing, provided that the specimens and the vessel are 3D printed using the same parameters. As a result, derivation of "effective" flexural and shear moduli, ignoring the non-isotropic behaviour of the material is adequate for the purposes of such an investigation. The developing capabilities of 3D printers allow an expanding range of materials to 
be used. Consequently, future work could potentially include different materials and other applications of complex thin-walled structures.

\section{Acknowledgements}

The present investigation was funded by the Lloyd's Register Foundation University Technology Center on Ship Design for Enhanced Environmental Performance. Financial support was also received from the EPSRC Doctoral Training Partnership (DTP 15, Grant reference: EP/M508147/1).

\section{References}

\section{References}

[1] G. Storhaug, Š. Malenica, B.-K. Choi, S. Zhu, and O. A. Hermundstad, "Consequence of whipping and springing on fatigue and extreme loading for a 13000TEU container vessel based on model tests," in 11th International Symposium on practical design of ships and other floating structures, (Rio de Janeiro), pp. 1201-1209, 2010.

[2] S. E. Hirdaris, G. W. Price, and P. Temarel, "Two- and three-dimensional hydroelastic modelling of a bulker in regular waves," Marine Structures, vol. 16, no. 8, pp. 627-658, 2003.

[3] I. Senjanović, I. Ćatipović, and S. Tomašević, "Coupled flexural and torsional vibrations of ship-like girders," Thin-Walled Structures, vol. 45, no. 12 , pp. 1002-1021, 2007.

[4] H. Houtani, Y. Komoriyama, S. Matsui, M. Oka, H. Sawada, Y. Tanaka, and K. Tanizawa, "Designing a hydro-structural model ship to experimentally measure its vertical-bending and torsional vibrations," in 8th International Conference on Hydroelasticity in Marine Technology, (Seoul, Korea), 2018.

[5] J. Zhou, S. Wen, F. Li, and Y. Zhu, "Coupled bending and torsional vibrations of non-uniform thin-walled beams by the transfer differential transform method and experiments," Thin-Walled Structures, vol. 127, no. March, pp. 373-388, 2018.

[6] A. Marón and G. K. Kapsenberg, "Design of a ship model for hydro-elastic experiments in waves," International Journal of Naval Architecture and Ocean Engineering, vol. 6, pp. 1130-1147, jan 2014.

[7] B. W. Kim, K.-H. Kim, Y. S. Kim, and S. Y. Hong, "Torsion Moment Conversion Methods in Model Test With U-shape Backbone," vol. 3, pp. 782$791,2014$. 
[8] S. Zhu, M. Wu, and T. Moan, "Experimental investigation of hull girder vibrations of a flexible backbone model in bending and torsion," Applied Ocean Research, vol. 33, no. 4, pp. 252-274, 2011.

[9] H. H. Sun and C. Guedes Soares, "An experimental study of ultimate torsional strength of a ship-type hull girder with a large deck opening," Marine Structures, vol. 16, no. 1, pp. 51-67, 2003.

[10] A. Lanzotti, M. Grasso, G. Staiano, and M. Martorelli, "The impact of process parameters on mechanical properties of parts fabricated in PLA with an open-source 3-D printer," Rapid Prototyping Journal, vol. 21, no. 5, pp. 604-617, 2015.

[11] J. F. Rodríguez, J. P. Thomas, and J. E. Renaud, "Mechanical behavior of acrylonitrile butadiene styrene (ABS) fused deposition materials modeling," Rapid Prototyping Journal, vol. 9, no. 4, pp. 219-230, 2003.

[12] A. Grammatikopoulos, J. Banks, and P. Temarel, "Experimental dynamic properties of ABS cellular beams produced using additive manufacturing," in ECCM18 - 18th European Conference on Composite Materials, (Athens, Greece), 2018.

[13] J. L. Colón Quintana, A. Redmann, G. A. Mazzei Capote, A. Pérez-Irizarry, A. Bechara, T. A. Osswald, and R. Lakes, "Viscoelastic properties of fused filament fabrication parts," Additive Manufacturing, vol. 28, no. February, pp. 704-710, 2019.

[14] T. G. Carne, D. T. Griffith, and M. E. Cassias, "Support Conditions for Free Boundary-Condition Modal Testing," IMAC-XXV:A Conference 8 Exposition on Structural Dynamics, no. January 2015, 2007.

[15] D. J. Ewins, "Modal Testing: Theory, Practice and Application," 2000.

[16] "ASTM E1876-15: Standard Test Method for Dynamic Young's Modulus, Shear Modulus, and Poisson's Ratio by Impulse Excitation of Vibration," 2015.

[17] "ISO 178:2001: Plastics-Determination of flexural properties," 2003.

[18] R.-Z. Chen, S.-X. Du, Y.-S. Wu, J.-R. Lin, J.-J. Hu, and Y.-L. Yue, "Experiment on extreme wave loads of a flexible ship model," in Practical Design of Ships and Other Floating Structures. Proceedings of the Eighth International Symposium on Practical Design of Ships and Other Floating Structures, vol. 2, pp. 871-878, 2001.

[19] A. A. Ozdemir and S. Gumussoy, "Transfer function estimation in system identification toolbox via vector fitting," IFAC-PapersOnLine, vol. 50, no. 1, pp. 6232-6237, 2017. 


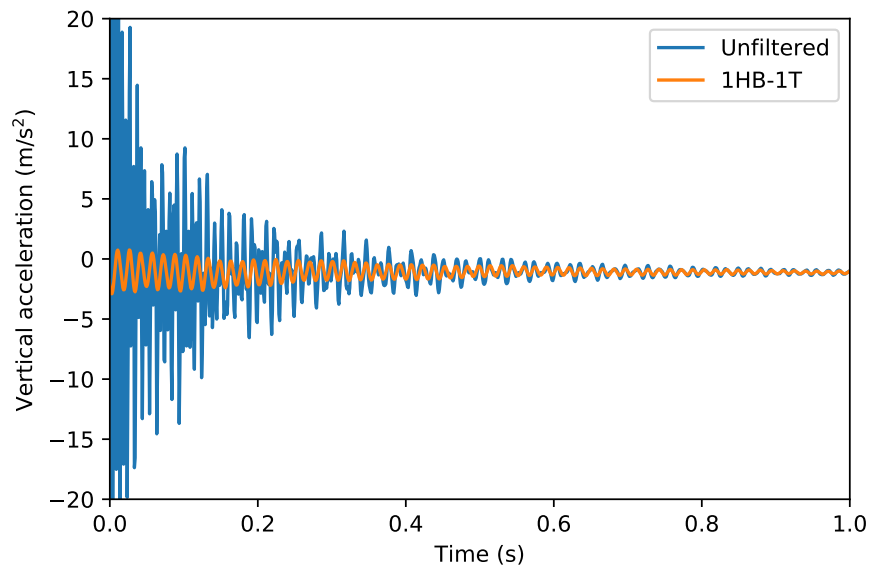

(a) Time signal
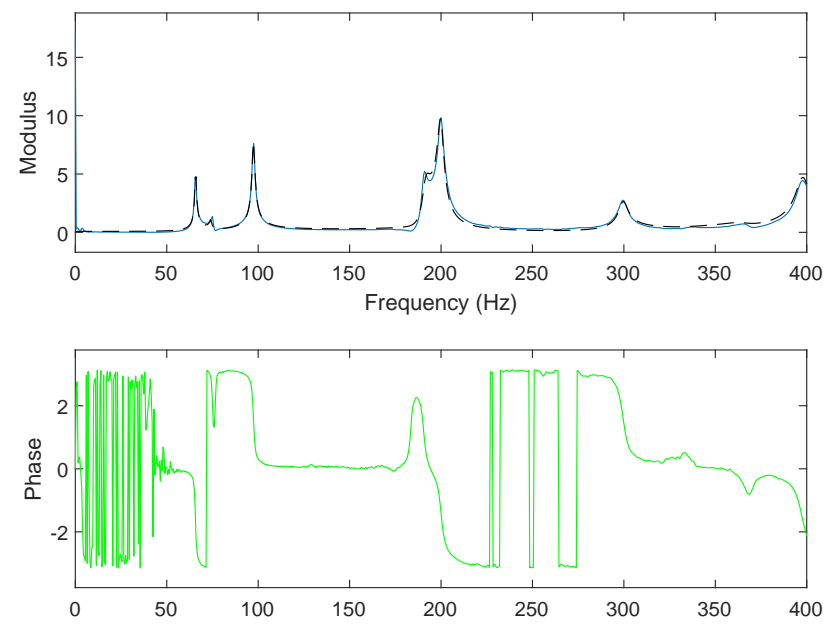

(b) Frequency response function

Figure 9: An example of the vertical acceleration response of the container ship model under vertical excitation. The top subfigure shows the unfiltered vertical acceleration signal in blue and the response of the first mode in orange, produced by using a low-pass filter at $70 \mathrm{~Hz}$. The bottom subfigure shows the frequency response function, where the blue continuous curve depicts the measured FRF and the black dashed curve corresponds to the FRF generated from the estimated damping coefficients. 


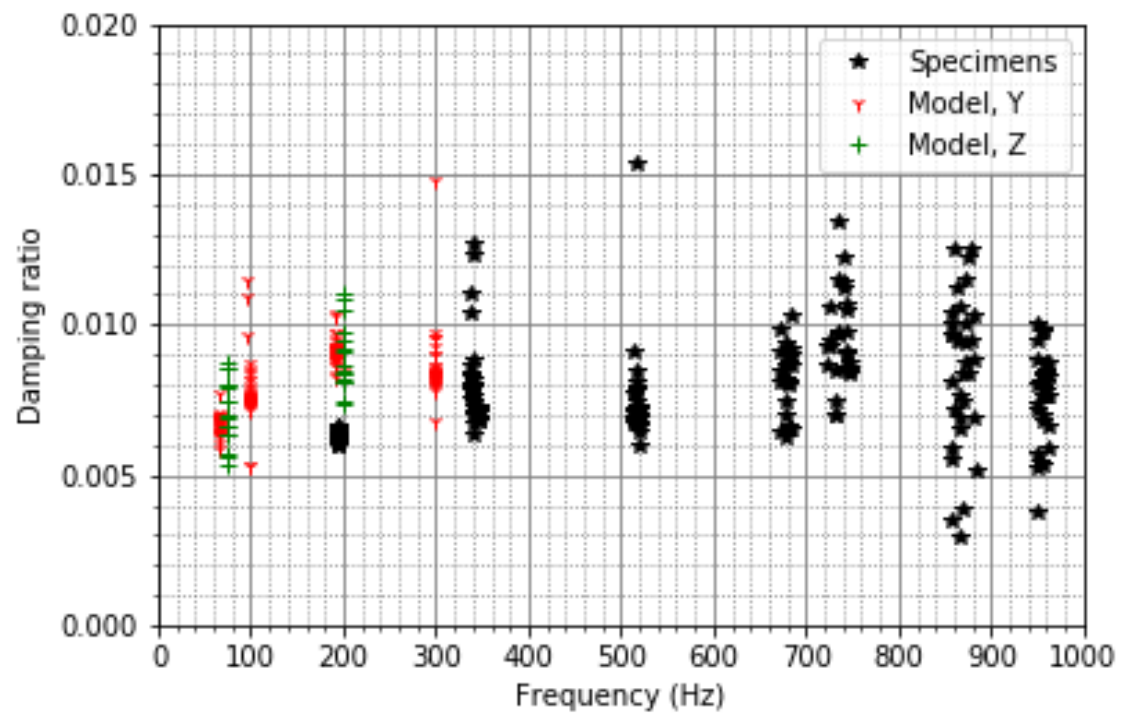

Figure 10: The damping ratios for various natural frequencies. Black star-shaped, red Yshaped and green cross-shaped markers correspond to specimen testing, container ship excited from the side (antisymmetric modes) and container ship excited from top (symmetric modes), respectively. 